\title{
Asian wasp envenomation and acute renal failure: a report of two cases
}

\author{
Rabindra Nath Das, ${ }^{*}$ Keka Mukherjee
}

\begin{abstract}
Acute renal failure is an unusual complication of wasp stings. We report two cases of renal failure after multiple wasp stings (Vespa affinis). Both patients had evidence of intravascular haemolysis, hepatic dysfunction, oligo-anuria and azotaemia and required dialysis. The first patient had severe hemolysis, rhabdomyolysis, pigment and venom nephropathy and died on the 8th day in hospital. The second patient, who recovered completely in 3 weeks time with steroid and antihistaminic therapy, had interstitial nephritis. Although acute renal failure after wasp stings is typically caused by acute tubular necrosis (ATN) in the setting of haemolysis or rhabdomyolysis, in some patients, acute renal failure may result from a direct nephrotoxic effect or acute interstitial nephritis from a hypersensitivity reaction.
\end{abstract}

KEYWORDS: Wasp envenomation, rhabdomyolysis, interstitial nephritis, acute renal failure, Nepal.

\section{INTRODUCTION}

In the Pokhara Valley, Nepal, there are many unpublished cases of wasp poisoning which take a heavy death toll annually. Wasp stings usually cause local allergic reactions but can sometimes lead to intravascular haemolysis, rhabdomyolysis, thrombocytopenia, acute tubular necrosis, acute hepatic injury (1) and even myocardial infarction (2) in addition to various respiratory and neurological (3) manifestations.

Death from wasp envenomation is a rare event and results from acute renal failure (ARF) involving various mechanisms. Although ARF after wasp stings is typically caused by ATN in the setting of haemolysis or rhabdomyolysis, in some patients, renal failure may result from a direct nephrotoxicity of wasp venom or acute interstitial nephritis from a hypersensitivity reaction. We here we report two cases of acute renal failure after wasp stings (Vespa affinis).

*To whom correspondence should be addressed: Dr. Rabindra Nath Das

Manipal Teaching Hospital,Pokhara,Nepal

Pokhara, MidWestern, Nepal

Email: das_rabindranath@hotmail.com

\section{CASE 1}

A 55-year-old farmer who had been collecting fodder from a jungle was admitted with dyspnea, hoarse voice and myalgia within 8 hours of being attacked by several wasps. The patient was given intravenous saline, oxygen, salbutamol ( $\beta 2$-adrenergic receptor agonist), chlorpheniramine (antihistamine), cyproheptadine (antihistamine), prednisolone (corticosteroid) and ranitidine (histamine $\mathrm{H} 2$-receptor antagonist). He also received fluid, mannitol and furosemide. By the next morning he had haemoptysis and had produced $400 \mathrm{ml}$ of dark urine. On examination, the patient was drowsy, pale, icteric and cyanosed and had approximately one hundred and fifty red and swollen sting marks all over the body. Systemic examination revealed polyphonic wheezes and crepitations at the base of the right lung. Investigations are shown in Table 1 . The onset of the oliguric phase was at 12 hours postenvenomation. Chest radiograph showed right basal consolidation. He died on the 8th day following admission despite aggressive therapy with medication, blood transfusions, assisted ventilation, and 16 cycles of dialysis.

\section{CASE 2}

A 40-year-old forest guard was attacked by a swarm of wasps. He presented with approximately twenty-five 
sting marks in exposed areas of face, throat, hands and legs [Fig.1]. The patient was treated in the primary health centre with rubbing of saliva and papaya slices over the sting marks and referred to teaching hospital almost 24 hours after being stung. He developed anuria and had not passed any urine the previous night. On examination, the patient had a rapid pulse, unrecordable blood pressure, icterus, an urticarial rash in exposed parts of the face, legs and hands, facial puffiness, and a swollen left ankle and right knee joint. The rest of the physical examination was unremarkable. Investigations are shown in Table 1. He was treated with oxygen, salbutamol, chlorpheniramine, cyproheptadine, prednisolone and ranitidine. His hepatic and renal function improved gradually with fluid challenge, furosemide, mannitol, bicarbonate infusion, dopamine, and 12 cycles of dialysis in 3 weeks' time.

\section{OBSERVATION}

\section{DISCUSSION}

Wasp stings are well-known causes of toxic and hypersensitivity reactions. Direct toxicity is rare, but has been reported in cases when a very large amount of venom is injected. Immediate hypersensitivity reactions, such as bronchospasm in the first case and an urticarial rash in the second, are known to occur. In our

Table 1: Pertinent lab results.

\begin{tabular}{|c|c|c|c|c|c|}
\hline \multicolumn{3}{|c|}{ Case 1 } & \multicolumn{2}{l|}{ Case 2 } & Normal Range \\
\hline Day (since admission) & 1 & 2 & 1 & 2 & \\
\hline Blood Count & & & & & \\
\hline Hemoglobin & 9.8 & & 11.2 & & $12.5-14.5 \mathrm{~g} \%$ \\
\hline WBC & 11800 & & 12480 & & $\begin{array}{c}4000-11000 \\
\text { cells/cm }\end{array}$ \\
\hline Eosinophils & & & $37 \%$ & & $1-5 \%$ \\
\hline Reticulocytes & & & $4 \%$ & & $0.2-2 \%$ \\
\hline Prothrombin Time (sec) & 78 & 20 & 28 & 14 & 12.5 \\
\hline Urinalysis & & & & & \\
\hline Specific Gravity & 1.028 & & 1.016 & & $1.002-1.018$ \\
\hline Albumin & + & & + & & nil \\
\hline WBC & $6-8$ & & $2-4$ & & $1-2 / \mathrm{hpf}$ \\
\hline RBC & $10-14$ & & $1-2$ & & nil/hpf \\
\hline Hb & + & & & & nil \\
\hline Urinary Myoglobin & 728 & & 6 & & $0-5 \mathrm{ng} / \mathrm{mL}$ \\
\hline Culture & - & & - & & sterile \\
\hline Renal Failure Index & & 3.00 & & 2.98 & \\
\hline Urinary Na+ & & 50 & & 42 & $\begin{array}{c}50-250 \\
\mathrm{mEq} / \mathrm{L} / \mathrm{day}\end{array}$ \\
\hline FE Na+ & & 2.65 & & 2.90 & \\
\hline
\end{tabular}

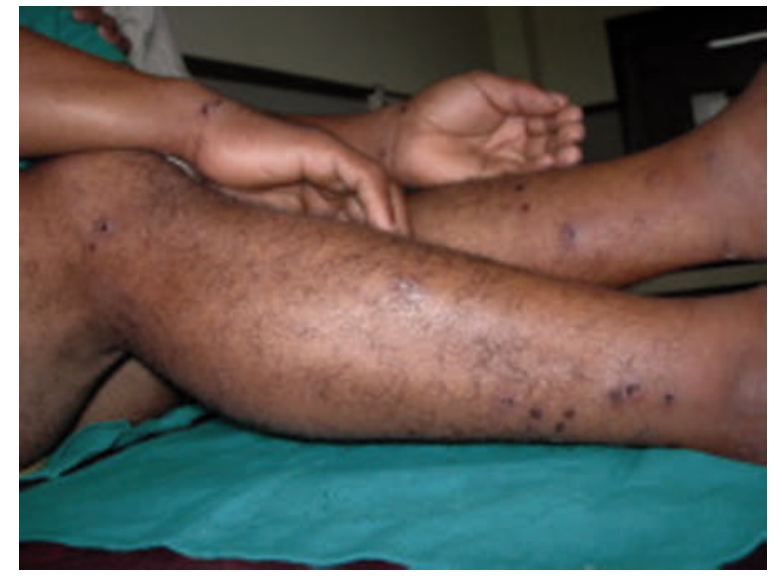

Figure 1: Case 2: Multiple stings \& swollen joints.

\begin{tabular}{|c|c|c|c|c|c|}
\hline & \multicolumn{1}{l|}{ Case 1} & \multicolumn{1}{ll}{ Case 2} & Normal Range \\
\hline Day (since admission) & 1 & 2 & 1 & 2 & \\
\hline Blood Gases & & & & & \\
\hline $\mathrm{pH}$ & 7.28 & & & & $7.35-7.45$ \\
\hline $\mathrm{PaO}^{2}$ & 88 & & & & $75-100 \mathrm{mmHg}$ \\
\hline $\mathrm{PaCO}^{2}$ & 38 & & & & $35-45 \mathrm{mmHg}$ \\
\hline $\mathrm{HCO}_{3}{ }^{-}$ & 22 & & & & $22-28 \mathrm{mEq} / \mathrm{L}$ \\
\hline General Chemistry & & & & & \\
\hline $\mathrm{K}^{+}$ & 6.4 & 7.2 & 5.6 & 4.2 & $3.5-5 \mathrm{mEq} / \mathrm{L}$ \\
\hline $\mathrm{Ca}^{2+}$ & 8.8 & 8.2 & 9.6 & 10.5 & $8.5-10.5 \mathrm{mg} \%$ \\
\hline $\mathrm{PO}_{4}^{2-}$ & 4.2 & 4.6 & 4.2 & 4.6 & $3.0-4.5 \mathrm{mg} \%$ \\
\hline${ }^{2-}$ Urea & 112 & 224 & 76 & 55 & $0-20 \mathrm{mg} \%$ \\
\hline Creatinine & 5.6 & 13.9 & 3.6 & 2.4 & $0.5-1.5 \mathrm{mg} \%$ \\
\hline Bilirubin Indirect & 3.4 & & 2.5 & & $0.4-0.8 \mathrm{mg} \%$ \\
\hline Bilirubin Direct & 0.6 & & 0.7 & & $0.2-0.4 \mathrm{mg} \%$ \\
\hline Creatine Kinase & & 8400 & & 90 & $<17-167 \mathrm{U} / \mathrm{L}$ \\
\hline LDH & & 4500 & & 340 & $240-420 \mathrm{U} / \mathrm{L}$ \\
\hline AST & 1260 & 140 & 1188 & 78 & $0-40 \mathrm{U} / \mathrm{L}$ \\
\hline Serum Albumin & 1.8 & & 3.2 & & $3.5-5.0 \mathrm{~g} \%$ \\
\hline
\end{tabular}


report, both reactions responded to steroids and antihistaminics. The second patient had swollen joints indicating serum sickness-like reaction in a sensitized individual.

Wasp venom contains toxic melittin, apamine, phospholipases A1, hyaluronidase, acid phosphatase, histamine, and degranulating peptide mastoparan (4). These components have direct and indirect cytotoxic (hepatic, renal and myocyte membrane), hemolytic, neurotoxic and vasoactive properties, which can cause intravascular haemolysis and rhabdomyolysis $(5,6)$.

Wasp venom can cause ARF by several mechanisms, which include ATN, acute interstitial nephritis, pigment nephropathy resulting from rhabdomyolysis (myoglobinuria) or intravascular haemolysis (haemoglobinuria) and hypotension caused by an anaphylactic reaction $(7,8)$.

Previously rhabdomyolysis and renal ischemia were thought to be main causes of nephropathy. Sakhuja et al had postulated that direct toxic injury could be one of the possible mechanisms of ARF following wasp poisoning (9).

Many cases of rhabdomyolysis-associated ARF have been published, but those due to wasp stings are rare. The wasp venom has deleterious effect on renal tubules and glomeruli (albuminuria, haematuria and ARF), red blood cells (haemolysis, reticulocytosis, unconjugated hyperbilirubinaemia), muscles (rhabdomyolysis, elevated creatinine phosphokinase and lactate dehydrogenase, myoglobinuria) and liver (elevated transaminases, hypoalbuminaemia and prolonged prothrombin time) (10). Kularatne et al had described similar multi-organ failure with high mortality following wasp poisoning owing to direct toxic effect (11).

In the first case we presented, the patient had myalgia, indicating muscle injury as evidenced by elevated CPK, $\mathrm{LDH}$ and AST and myoglobinuria $(728 \mathrm{ng} / \mathrm{ml})$. He also had intravascular haemolysis and haemoglobinuria. Toxic pigments might have caused nephropathy resulting in ARF. The alternative mechanism of ARF postulated was direct nephrotoxicity by massive wasp venom.

Zhang $\mathrm{R}$ et al. (12) reported for the first time that acute tubulointerstitial nephritis could lead to ARF in wasp sting cases. In the second case we present, the patient had eosinophiluria, indicating interstitial nephritis. He recovered fully with the mentioned treatment. He did not report taking any medication which might have had nephrotoxic side-effects, and no other causes of ATN could be found. Ultrasound abdomen was unremarkable. Kidney biopsy revealed proximal peritubular necrosis and eosinophilic infiltration. Hence it can be hypothesized that the ATN was caused by a hypersensitivity reaction to the wasp venom.

\section{CONCLUSION}

Wasp stings pose a great environmental hazard in Nepal and early recognition of anaphylactic shock, hepatic or renal dysfunction, rhabdomyolysis or haemolysis and rapid transport to hospital are essential steps of management to avoid fatalities. ARF due to toxic or pigment nephropathy and tubulointerstitial nephritis should be considered in any oliguric and azotemic patient following wasp attack.

\section{COMPETING INTEREST}

The authors declare that they have no competing interests.

\section{AUTHOR'S CONTRIBUTION}

The second author KG managed the patients with dialysis and conceived the idea for the case report.

\section{ACKNOWLEDEMENT}

The Dean and CEO, Prof. Satish Dham had inspired the author to write this manuscript. Written informed consent was obtained from the patient's relatives for publication of the study. There is no source of funding for the study and for the manuscript preparation.

\section{REFERENCES}

1. Rejsman R E. Unusual reactions to insect stings.Curr Opin Allergy Clin Immunol. 2005 Aug; 5(4):355-8.

2. Levine HD. Acute Myocardial Infarction following wasp stings. Am Heart J. 1976; 91:365-374.

3. Day JM. Death due to cerebral infarction after wasp stings. Arch Neurol. 1962 Sep; 7:184-186.

4. King TP,Jim SY,Wittowski KM. Inflammatory role of two venom components of yellow jackets (Vespula vulgaris): a mast cell degranulating peptide mastoparan and phospholipase A1.Int Arch Allergy Immunol. 2003 May; 131(1):25-32.

5. Hoffman DR. Hymenoptera venom proteins. Adv Exp Med Biol. 1996; 391:169-186.

6. Koffler A, Friedler RM, Massry SG. Acute renal failure due to nontraumatic rhabdomyolysis. Ann Intern Med 1976; 85:23-28.

7. Nace L, Bauer P, Lelarge P, Bollaert PE, Larcan A, Lambert H. Multiple European wasp stings and acute renal failure. Nephron. 1992; 61:477.

8. Perz-Pimiento AJ,Gonzalez-Sanchez LA,,Prieto-Lastra LRodrguez-Cabriros M I,IglesiasCadarso A,RodriguezMosquera M. Anaphylaxis to hymenoptera sting: study of 113 patients. Med Clin (Barc). 2005 Oct 1; 125(11):417-20.

9. Sakhuja V, Bhalla A, Pereira BJ, Kapoor MM, Bhusnurmath SR, Chugh KS. Acute Renal Failure following multiple hornet stings. Nephron. 1988; 49:319-321.

10. Thiruventhiran T, Goh BL, Leong CL, Cheah PL, Looi LM, Tan SY. Acute renal failure following multiple wasp stings. Nephrol Dial Transplant 1999; 14:214-217.

11. Kularatne SA,Gawaramamana IB,de Silva PH. Severe multi- 
organ dysfunction following multiple wasp (Vespa affinis) stings. Ceylon 2003 Dec; 48(4):146-7.

12. Zhang R, Meleg-Smith S, Batuman V. Acute tubulointerstitial nephritis after wasp stings. Am J Kidney Dis. 2001; 38:e33.

13. Vikrant S, Pandey D, Machhan P, Gupta D, Kaushal SS, Grover $\mathrm{N}$. Wasp envenomation-induced acute renal failure: a report of three cases. Nephrology. 2005; 10:548-52.

R.N. Das, MBBS, MD, MRCP(UK), FRCP(London) is presently working as an Associate professor Department of Medicine, Manipal Teaching Hospital, Pokhara, Nepal. He graduated from the medical college of Calcutta University. He obtained his post graduate degree from a premier institute in India, PGIMER; Chandigarh. He has more than 17 years of work experience in different branches of clinical medicine especially tropical and infectious diseases in several hospitals in India, Middle East, United Kingdom and Nepal.

Keka Mukherjee worked with the first author in the medical ward and searched the bibliography for this article. She graduated in December 2006 from Kathmandu University. She is interested in renal diseases. 